\title{
MÚSICA Y JARDINES EN GRANADA. LA IMPRONTA FRANCESA DE DEBUSSY Y FORESTIER EN LA CREACIÓN ARTÍSTICA ESPAÑOLA
}

\author{
MUSIC AND GARDENS IN GRANADA. DEBUSSY AND FORESTIER'S \\ FRENCH MARK IN SPANISH ARTISTIC CREATION
}

\author{
Laura Sanz García \\ Universidad Alfonso X el Sabio \\ 1sanz@myuax.com \\ ORCID iD: https://orcid.org/0000-0003-0738-9218
}

\begin{abstract}
Resumen
El objetivo de este artículo es ahondar en los aspectos que relacionan la creación de músicos y jardineros, españoles y franceses, en torno a la imagen de España, y la importancia del jardín en la inspiración visual de la música impresionista. Para ello se analizan los paralelismos temáticos y estilísticos existentes en la obra de dos artistas franceses, el músico Claude Debussy y el paisajista JeanClaude Nicolas Forestier, en relación con el exotismo andalusí, y concretamente los jardines de Granada.

Al interés compartido por un imaginario que, para ambos creadores, representa la esencia de lo español, se une una misma intención renovadora y toda una serie de estilemas que traducen en términos artísticos su personal interpretación de Al-Andalus. Por otra parte, la influencia que tanto Debussy como Forestier ejercieron en los artistas españoles -como Falla y Javier de Winthysen-, conecta una vez más a Francia con el desarrollo de nuestras artes.

De este análisis interdisciplinar se deduce una sensibilidad común en el eje España-Francia y entre artes aparentemente tan alejadas como la música y la jardinería. Debussy y Forestier, así como sus "discípulos" españoles, pretenden combatir las imágenes románticas de España, utilizando el tópico hispanoárabe para renovar sus respectivos lenguajes, en la música y la arquitectura del paisaje, en la transición al siglo XX.
\end{abstract}

\section{Palabras clave}

Claude Debussy, J.C.N. Forestier, impresionismo musical, arquitectura del paisaje, sinestesia, relaciones culturales EspañaFrancia, jardín hispanoárabe, Granada, Manuel de Falla, Javier de Winthuysen.

\begin{abstract}
This article aims to delve into the aspects that connect both Spanish and French musicians and landscapers' works around the cultural image of Spain, as well as the importance of gardens in the visual inspiration of impressionist music. For that purpose, the text presents an analysis of the thematic and stylistic parallelisms between two outstanding French artists, the composer Claude Debussy and the landscape architect Jean-Claude Nicolas Forestier, in relation to the Arab-Andalusian exotism and, more specifically, to the gardens of Granada.

To their common interest in representing the authentic essence of all that is Spanish, one should add the same avant-garde intention and a series of themes that translate into artistic terms their personal interpretation of Al-Andalus. On the other hand, the influence exercised by Debussy and Forestier on the Spanish artists -such as Falla and Javier de Winthuysen-, relates France once more to the development of modern art and music in Spain.

This interdisciplinary analysis reveals a common sensibility in the axis France Spain and between two artistic disciplines apparently uneven as music and gardening. Debussy and Forestier, as well as their Spanish "disciples", intend to overcome the romantic images of Spain, using the Hispano-Arabic cliché to update their respective artistic languages, in music and landscape architecture, in the transition to the 20th century.
\end{abstract}

\section{Key words}

Claude Debussy, J.C.N. Forestier, musical impressionism, landscape architecture, synesthesia, cultural relationships SpainFrance, Hispano-Arabic gardens, Granada, Manuel de Falla, Javier de Winthuysen. 
La configuración de una identidad propia en el arte español de la Edad de Plata denota, como se ha estudiado en innumerables ocasiones, el influjo de la mirada francesa, a través de los intercambios personales y teóricos con los círculos artísticos de París. El papel determinante de Francia en la renovación del tópico español se manifestó en muy diversos ámbitos de la cultura en las primeras décadas del siglo XX. En este trabajo pretendo abordar el análisis comparado de un fenómeno, la atracción por la Granada nazarí, que pone de manifiesto los vínculos estéticos de la música con la jardinería o la arquitectura del paisaje, y por supuesto con la pintura a través del impresionismo.

\section{UNAS CONSIDERACIONES PREVIAS EN TORNO A LA MÚSICA Y EL ARTE DE LOS JARDINES}

Las correlaciones estéticas que enlazan la arquitectura con la música han sido ampliamente analizadas a lo largo de la historia. Entre las afinidades más inmediatas que unen música y arquitectura está, por ejemplo, su carácter no representativo frente a otras artes, o la componente matemática de ambas -recuérdese la composición la composición del motete de Dufay Nuper Rosarum Flores según las mismas proporciones matemáticas de la cúpula de Brunelleschi en Florencia. Esto otorga en los dos casos una importancia especial a la estructura formal de la obra, ya sea el edificio o la obra musical, que nos obliga a utilizar un lenguaje muy específico y a menudo abstracto para analizar sus productos. Y, desde el punto de vista de la percepción, no debemos olvidar el carácter envolvente de ambas experiencias estéticas, ya sea por su dimensión espacial o temporal.

Estos lazos se fortalecen cuando comparamos la experiencia musical con la arquitectura de jardines, pues es aquí donde lo espacial y lo temporal se alían para ofrecernos una obra de arte tan frágil como sugerente. En efecto, en el jardín el aspecto temporal es tan importante como el espacial, pues sólo el tiempo puede modelar y llevar a su forma definitiva el elemento vegetal, vivo y dinámico, de igual modo que el tiempo (y la falta de cuidados) puede ser el peor enemigo del jardín. Además, el tiempo tiene una importancia especial en la percepción del jardín, en concreto a través del paseo como parte esencial de esta experiencia estética. El land art, ya en la segunda mitad del siglo XX, ha explorado repetidamente el tema del recorrido y el tiempo en el paisaje: en 1967 Richard Long realiza A Line Made by Walking, una línea dibujada hollando la hierba de un prado, y Robert Smithson termina A Tour of the Monuments of Passaic. El carácter efímero del land art y la necesidad de algún medio de grabación o fotografía para dejar testimonio de él refuerza su dimensión temporal y lo acerca a la experiencia musical.
Es bien conocida, por otra parte, la búsqueda secular de artefactos musicales para adornar el jardín, sobre todo a partir del Renacimiento. Alfredo Aracil nos recuerda algunos de esos artificios sonoros que han contribuido históricamente a la experiencia multisensorial del jardín:

-Bernard Palissy (Receta verdadera..., 1563) pretende evocar el canto de los pájaros a través de unos flautines sumergidos bajo el agua, que se unen a un "órgano eólico" y otros ingenios que recrean el croar de las ranas o el murmullo del agua ${ }^{1}$.

-Los órganos hidráulicos y fuentes sonoras de los jardines italianos (Villa d'Este, Villa de Pratolino) se contagiaron por toda Europa durante el manierismo.

-Felipe II hizo instalar pajareras en los puentes de acceso al palacete de El Pardo para escuchar su canto.

-En el imaginario simbolista del s. XIX destaca la novela de Joris-Karl Huysmans À rebours, y su "decadente micro-universo de luces, formas, olores y sueños artificiales de Des Esseintes"2.

Según Alfredo Aracil, "el tiempo es el soporte de la música y el intérprete del jardín; intérprete en su sentido más musical: el que hace posible que el proyecto de su creador se manifieste ante los demás. Quizá por eso el jardín es tan delicado de reflejar en un pentagrama y, sin embargo, tan frecuentemente evocado"3. El mismo autor nos pone sobre la pista del tema abordado aquí, el de la relación entre jardín, música e identidad: "la mirada, el cuadro, el poema o la música sobre un jardín o un paisaje nos desvelará sobre nosotros mismos, sobre quien mira, pinta, escribe o compone, tanto o más que sobre el paisaje evocado del jardín"4.

Otro musicólogo, Jorge de Persia, ha reparado en esta inspiración que el jardín ejerce en todas las artes, y que a menudo completa su significado: “... jardín y paisaje son entidades que adquieren perspectiva y proyección a través del arte, la pintura, la arquitectura y, por qué no, de la música, siempre a partir de lo natural y a través de un proceso ideológico"s.

\section{EL JARDÍN EN LA MÚSICA IMPRESIONISTA}

La idea del jardín como arte y lugar donde confluyen los cinco sentidos cobra pleno significado en el contexto del

1 ARACIL, Alfredo (2003): 14-15.

2 ARACIL, Alfredo (2003): 17.

3 ARACIL, Alfredo (2003): 29.

4 ARACIL (2003): 29.

5 PERSIA (2003b): 160. 
impresionismo. El jardín de Claude Monet en Giverny, auténtico laboratorio para las experimentaciones cromáticas del pintor, o el estímulo visual de los músicos impresionistas en sus imágenes sonoras nos trasladan a una primera búsqueda de evocaciones sinestésicas, en dirección a la idea de "arte total" que marcará el siglo XX.

El motivo del jardín, con o sin personajes, íntimo o público, le permite a Monet jugar con la luz y el color según la hora del día o la climatología. Así comienza a trabajar en las series como El estanque de los nenúfares o la serie de los lilos (Le repos sous les lilas, 1873, Lilos al sol). En concreto, el jardín de Giverny está concebido según Caroline Stefulesco como inspiración para las investigaciones cromáticas de Monet: es en realidad un laboratorio del color con sus borduras de variadas vivaces cuyo colorido, más sutil o brillante, cambia con las estaciones ${ }^{6}$. Monet muestra una verdadera afición por la jardinería y la botánica, en una constante retroalimentación con su actividad artística, lo que explica la "excepcional veracidad" de sus jardines pintados.

Del mismo modo que Monet y otros pintores salen al aire libre para pintar sus cuadros, los músicos de la órbita del impresionismo recurren con frecuencia al paisaje en busca de inspiración. Así, Respighi sigue los pasos de Monet en Le Fontane di Roma, 1916, evocando musicalmente el efecto de la luz sobre las fuentes en distintos momentos del día; en I Pini di Roma, 1924, volverá a inspirarse en los paisajes urbanos de la ciudad eterna. Ravel busca con frecuencia el reflejo y el sonido del agua en sus obras, como bien lo muestran los Jeux d'eau para piano (1901) o la obra Miroirs (piano, 1904-05).

En concreto, es Debussy quien con más frecuencia se inspira en la naturaleza, y particularmente en los jardines: "Jardins sous la pluie" (Estampes, 1903), "Reflets dans l'eau" (Images I, 1905), "Cloches à travers les feuilles" (Images II, 1907-8), "Les sons et les parfums tournent dans l'air du soir" (Préludes I, 1909-10), "Feuilles mortes" y "La terrasse des audiences du clair de lune" (Préludes II, 191013) son ejemplos de su catálogo para piano. Pero este interés se traslada también a la música orquestal -con Printemps (1887-1908); "Rondes de printemps" (Images para orquesta, 1906-11) - las obras vocales -"Dans le jardin" (1891, Gravollet), "Le balcon" o "Le jet d'eau" en Cinq poèmes de Baudelaire (1887-89)-, y tantas otras de inspiración floral o paisajística.

Las primeras analogías entre la pintura de Monet y la música de Debussy -en otros aspectos, más cercano al simbolismo- se ven en sus fuentes de inspiración: la pre-

6 STEFULESCO (1995): 281. ocupación por el color y el timbre, la predilección por los elementos acuáticos (reflejos, espejos, movimientos de olas) y la naturaleza cambiante de las cosas en función de la luz, que propicia el uso de ciertos temas en forma de serie ( $\mathrm{La}$ catedral de Rouen de Monet; La mer o Nuages de Debussy).

Especialmente relevante es la atracción de Monet, y sobre todo Debussy, por las culturas de raíz oriental pues, como nos recuerda Consuelo Martínez Correcher ${ }^{7}$, también en la jardinería la búsqueda de lo exótico se dirige con frecuencia hacia lo japonés, lo ruso y lo español. Recuérdese el jardín de Giverny, y su puente japonés sobre el estanque de los nenúfares; en las "Pagodes" (Estampes, 1903) de Debussy resuenan ecos de los jardines orientales que comienzan a influir en el paisajismo europeo, y que invaden los grabados y acuarelas de Extremo Oriente. Entre estos jardines se encuentra el que diseña Edouard André para Albert Khan en París, un conjunto de kioscos, riachuelos y elevaciones, y de nuevo el "Clos Normand" de Monet con sus "reflejos azules del agua, bajo el orientalizado puente de especialísimo verde, donde sumergidos emergen despaciosamente los nenúfares amarillos, rosas, blancos, todo conmovido por la luz"

\section{GRANADA Y SUS JARDINES COMO FUENTE DE INSPIRACIÓN MUSICAL A PARTIR DE 1900}

En el ámbito de las relaciones hispanofrancesas, el comienzo del siglo XX contará con notables representantes en la música y el paisajismo, y en ambos casos Granada tendrá un papel central. Color, sensualidad, identidad... son contenidos esenciales en la música de Falla y Debussy que explican la orientación de ambos autores hacia el mundo de los jardines; más concretamente, hacia la atmósfera misteriosa de los jardines y paisajes andaluces. Lindaraja, Soirée dans Grenade o Les parfums de la nuit de Debussy y, por supuesto, Noches en los jardines de España, son muestras de este fenómeno que trato de analizar aquí.

Louis Jambou expresa muy bien el poder evocador del jardín, y concretamente de los jardines de la Alhambra: “...el jardín es aquí prolongación de la arquitectura, representación del universo y fiel reflejo de los movimientos interiores del alma. Se domestica y se interioriza, es decir, se idealiza", a través de su carácter cerrado e íntimo. Este jardín-patio representa, por tanto, una vivencia del espacio propia de la cultura musulmana, que se repliega hacia el interior de la vivienda.

7 MARTÍNEZ CORRECHER (2003): 70 8 MARTÍNEZ CORRECHER (2003): 70 9 JAMBOU (2003): 33. 
No obstante, otros autores han cuestionado la fuerza del jardín como fuente de identidad. Jorge de Persia opone el carácter identitario del paisaje del 98 al lenguaje poético del jardín, que tradujo en pintura Santiago Rusiñol. Y, sin embargo, el mismo autor reconoce que "lo que impresionó a los modernistas españoles [del jardín] era su capacidad para almacenar el tiempo, para guardar esencias tangibles de la historia; [...] es un conservatorio de esencias que, como en el jardín bíblico, guarda la capacidad de dar vida, de renovarla" 10 . Entre estos modernistas "jardineros" se encuentran el poeta músico y artista Apeles Mestres -amigo de Falla- y Juan Ramón Jiménez, que colaboró con Winthuysen en el diseño de uno de los jardines de la Residencia de Estudiantes, compartiendo así la afición jardinera de reconocidos músicos como Albéniz y Granados. Si al poder de evocación de los jardines se une la sensualidad exótica de Al-Andalus, se comprende la atracción de Debussy, Falla y J.C.N. Forestier por los jardines de la Alhambra. En efecto, a comienzos del siglo XX estaba más vigente que nunca la imagen de una España mora, reforzada por algunos espectáculos celebrados en el seno de las Exposiciones Universales. En la exposición de 1889 en París, Debussy y Dukas conocieron, además del gamelán balinés, una versión caricaturesca de nuestro folclore en forma de flamenco orquestal ${ }^{11}$, junto a otros ejemplos más "auténticos" de cante jondo bailados por niños y acompañados por guitarra.

A pesar de su pintoresquismo degradado, este exotismo andalusí siguió siendo la moda en París incluso a comienzos del siglo XX, como demostró el éxito, en la Exposición Universal de París de 1900, de la atracción "Andalucía en el Tiempo de los Moros": en ella se representaban escenas del "pasado andaluz" bajo el dominio musulmán. Estos espectáculos atrajeron la atención de todo el público, desde las clases proletarias hasta intelectuales como el crítico de arte Émile Verhaeren, que alaba en sus escritos la danza española e identifica el flamenco con la violencia y la voluptuosidad del alma hispana.

En este contexto, los músicos españoles afincados en París, encabezados por Viñes, Granados, Albéniz y Falla, liderarán ahora una moda renovadora de lo español, que inspira a autores como Debussy o Ravel obras españolistas. La coincidencia en el estreno de las Iberia de Debussy (1908) y de Albéniz (1909) sitúa a ambos autores en la búsqueda más profunda del pasado musical español, alejándose como nunca de los decorados de cartón piedra de la espagnolade para abrirse a un arte nacional que trasciende fronteras ${ }^{12}$. Y ello a pesar de que el único viaje de Debussy a España, en 1880, para asistir a una corrida de toros en San Sebastián, duró tan solo unas horas.

El contacto de Debussy con los músicos españoles le hace ver como irreal la imagen que ofrece la moda españolista, contaminada por sustancias extranjeras. Por ello renuncia Debussy a la españolada, llena de fórmulas, de Carmen (Bizet, 1875) y prefiere apelar al pasado rudo, arcaico, casi mítico, de Iberia. El rechazo del andalucismo romántico no impedirá que el impresionismo francés asuma nuevas ideas preconcebidas y erróneas sobre la música española, de las que el ejemplo más notable es la identificación de la habanera cubana con España. Albéniz, por su parte, evoca pueblos y barrios de España, principalmente andaluces, pero desde un lenguaje a menudo impresionista. Por ello, ambas llegan a un hispanismo universal que pretende la "asimilación intuitiva de un folclore recreado y elevado al rango de inspiración auténtica"13.

A pesar de los falsos tópicos asumidos por los músicos franceses, Manuel de Falla se manifiesta en contra del pintoresquismo descriptivo y prefiere la música evocadora de atmósferas iniciada por Debussy. Valora Falla de Debussy su capacidad para evocar las esencias de la música española, a pesar de su atracción por la habanera. La rápida popularización de este ritmo gracias a Carmen lo sitúa geográficamente en Andalucía. A partir de entonces, la habanera formará parte de la evocación española incluso en los autores más vanguardistas, respaldados por los propios españoles. Manuel de Falla justifica esta asociación porque "hasta cierto punto la habanera no es otra cosa sino el tango andaluz" "14; por ello, cuando Debussy imagina La Puerta del Vino de la Alhambra a ritmo de habanera, tendrá el vistobueno del maestro gaditano. Además, la música evocadora (que "no descriptiva ni pintoresca" 15 ) de Debussy simplifica al máximo los rasgos de habanera, que quedan reducidas al bajo ostinato del piano.

La primera referencia a Granada en la obra instrumental de Debussy es, sin embargo, la menos conocida Lindaraja para dos pianos (1901), cuyo título nos transporta al patio de mismo nombre perteneciente a la Alhambra y de estilo no nazarí, sino renacentista. En ella Debussy utiliza de nuevo el ritmo de habanera y armonías similares a las empleadas por Ravel en su habanera de 1895, pero el manuscrito de Lindaraja no sería publicado hasta 1926. En este caso, el ostinato que abre la obra dará paso a una breve sección de amplios arpegiados impresionistas y a otras de ritmos muy marcados, pero siempre a la sombra voluptuosa de la habanera.
10 PERSIA (2003b): 159.

11 VELLY (2003): 311

12 VELLY (2003): 308-310.
13 VELLY (2003): 311.

14 FALLA (1988): 75.

15 PERSIA (2003a): 100. 
La misma combinación de sensualidad y ensoñación, donde las melodías arabizantes se superponen al ritmo de habanera, puede escucharse en "Soirée dans Grenade" (Estampes, 1903) y "Les parfums de la nuit" ("Iberia", Images pour orchestre, 1910).

Los títulos de estas dos últimas obras de Debussy, y por supuesto las Noches en los jardines de España, ponen de manifiesto la fuerza expresiva de la tríada "noche- música-jardín" que, según Antonio Gallego ${ }^{16}$, provenía ya en Gustavo Adolfo Bécquer de la tradición hispánica. La carga poética de los tres conceptos se unen en las evocaciones de los jardines y calles granadinos, y se expresan musicalmente con los recursos del impresionismo: arpegios, escalas modales, imitaciones guitarrísticas, texturas casi desnudas que albergan melodías nostálgicas...

Del mismo modo, y también gracias al lenguaje impresionista, resulta fundamental el tratamiento del agua en la música de Liszt, Ravel y Falla, como bien señala Yvan Nommick:

... la liquidez del agua no implica necesariamente que el compositor la evoque a través de formas musicales en constante evolución. En efecto, del mismo modo que los estanques, fuentes y surtidores son a la vez movilidad e inmovilidad, el agua circula preferentemente en organismos musicales que adoptan formas basadas en la repetición variada y/o en la reexposición... ${ }^{17}$.

En cuanto a las Noches en los jardines de España de Falla, la paisajista Consuelo M. Correcher explica el porqué de esta atracción hacia el jardín nocturno:

Por las noches hay un mayor silencio, incluso el jardín se acalla, salvo el rumor del agua que suele prevalecer [...]. La visibilidad es menor aunque determinados elementos naturales pueden resaltar en la oscuridad. El tacto y el gusto permanecen neutrales y es invasor el perfume, incluso alguno es exclusivo de la noche. [...] En la noche, cuando menos se ven los jardines, es cuando más se imaginan, cuando más se intuyen, más se sueñan, cuando [se da] una mayor presencia del misterio... ${ }^{18}$.

Y si bien las Noches en los Jardines de España fueron compuestas antes de que Falla pudiera visitar Granada, la belleza de los jardines granadinos acompañaría a Falla a partir de 1925, cuando se instala Falla en su carmen situado

16 GALLEGO (2003): 112.

17 NOMMICK, Yvan (2003): 142.

18 MARTÍNEZ CORRECHER (2003): 93. al borde inferior del Campo de los Mártires. "Una casa pequeña, un jardín mínimo y todo lo anterior... y los amigos que allí están, Torres Balbás, García Lorca, García Gómez, los que vienen, Massine, Diaghilev, Landowska, y muchos otros" "19. En el contexto mágico de los cármenes granadinos se reúnen compositores, escritores, intérpretes, bailarines... en torno a la figura de Manuel de Falla.

También conocerá bien Falla el carmen de su vecino pintor, José María Rodríguez Acosta, jardín de estilo art decó que desafía la pendiente casi vertical del terreno para crear espacios íntimos de muros blancos y potentes topiarias de ciprés. O el Carmen de los Mártires, otro escenario habitual de fiestas para músicos, artistas y poetas, donde conviven desde el siglo XIX jardines de distintos estilos, desde el jardín formal francés al paisajista.

No es de extrañar, pues, que en los Jardines de España de Rusiñol -amigo común, por cierto, de Falla y de Winthuysen- los de Granada sean los más representados. Y de aquí precisamente tomará su inspiración Falla para componer sus Noches en los jardines de España.

\section{LA HUELLA ANDALUSÍ EN LOS JARDINES DE J.C.N. FORESTIER}

Este ambiente cultural explica el gran paralelismo que muestra la historia de la jardinería en España con el desarrollo estilístico de nuestro nacionalismo musical a comienzos del siglo XX. Mientras Falla reconoce la maestría de Debussy en sus evocaciones españolas, el pintor, más tarde paisajista, Javier de Winthuysen expresará su admiración por la obra del francés J.C.N. Forestier, autor de los proyectos del parque de María Luisa para la Exposición Iberoamericana de 1929 y el recinto ferial de Montjuïc para la Exposición Internacional de ese mismo año. El punto de partida de Forestier en esta búsqueda de lo genuinamente español era, del mismo modo que para Debussy, la Granada hispanoárabe.

En 1893, la Duquesa de Montpensier donó a la ciudad de Sevilla lo que sería la mayor parte de los terrenos del futuro Parque de María Luisa. En septiembre de 1911, el jardinero francés Jean-Claude Nicolas Forestier comenzó a remodelar los jardines existentes para albergar en ellos el recinto de la Exposición Iberoamericana que había de celebrarse en 1914, pero que la Gran Guerra obligó a postergar hasta 1929.

En 1914, el arquitecto español Aníbal González comenzó con los trabajos de construcción del recinto ferial, empezando por la Plaza de España. Los nuevos edificios de

19 MARTÍNEZ CORRECHER (2003): 88-89. 
la Plaza de España, en estilo regionalista sevillano, fueron usados como oficinas de la feria. Forestier se encargó del ajardinamiento del recinto, una superficie de $135.829 \mathrm{~m}^{2}$. El proyecto, de clara inspiración islámica, recoge algunos elementos tomados directamente de la Alhambra, como una Fuente de los Leones o el Estanque de los Lotos, réplica del Patio del Ciprés de la Sultana del Generalife. Pero lo más significativo es el planeamiento ortogonal que superpone al trazado paisajista del siglo XIX, racionalizando las circulaciones sin renunciar al encanto romántico del jardín original. Se funden así la tradición francesa de Le Nôtre, con las glorietas y juegos de agua propios del jardín hispanoárabe y la naturalidad inglesa ${ }^{20}$, que preside el conjunto desde el pintoresco Estanque de los Patos, foco central del parque. Pérgolas, azulejos y fuentes completan la decoración de este parque y de muchos de los jardines que Forestier dejó en España.

El eclecticismo que caracteriza el final del siglo XIX permitió a Forestier acercarse al jardín hispanoárabe y reconocer su valor, entendiéndolo como un caso particular de jardín mediterráneo. Forestier lo define como "el jardín del clima del naranjo que por la riqueza, delicadeza y equilibrio que lo caracterizan tanto lumínica, plástica, sonora como oloríficamente, constituye para muchas religiones la plena realización del paraíso terrenal". Sin embargo, "su enamoramiento mediterráneo no produciría por ello su pérdida de identidad francesa, sino más bien le serviría para reelaborar y resolver definitivamente su síntesis definitiva: integrar perfectamente los jardines del llano y de la pendiente" 21 .

Forestier afirma que, de todo el arte hispano musulmán, "los jardines marcaron el alto grado de la civilización de este país", considerando a la jardinería un arte más sutil que la arquitectura. Este jardín se apoya en tres pilares:

1. El agua, signo de riqueza y poder precisamente por su carestía, y motivo de placer, "porque va acompañada de una vegetación exuberante, de sombras, de perfumes, de frutas, de flores abundantes y magníficas, porque refresca, porque apaga la sed". Por ello el agua no se recluye en conductos sino que se exhibe todo lo posible, en canales, fuentes y estanques.

2. El perfume como parte esencial de su composición: naranjos, jazmines, rosales, madreselvas, retamas, dondiegos de noche y Cestrum nocturnum (damas de noche) despliegan sus aromas a lo largo de las estaciones, en distintos momentos del día o de la noche, dando a los jardines andaluces su carácter sensual y delicado.

3. El trazado rectangular y simétrico, más pequeño que el jardín francés, en el que

los grandes conjuntos se obtienen multiplicando este elemento en un dibujo cuadriculado, ampliando algunas avenidas siempre sobresalientes, variando la forma de los estanques, incorporando mil fantasías ingeniosas en el curso de agua exhibida y conducida de un extremo a otro del terreno, de terraza en terraza ${ }^{22}$.

El jardín meridional resulta ser así un hortus conclusus, que busca la intimidad de la vivienda. El mérito de Forestier consiste, precisamente, en el intento de integrar los elementos culturales "exóticos" en un marco estilístico y formal de mayor complejidad y amplitud, el de la herencia clásica de Le Nôtre. Esto no evita que desde nuestra perspectiva su obra parezca trivializar eventualmente el tópico andalusí, pero hay que reconocer la voluntad de Forestier de trascender la anécdota para evocar la esencia de nuestro jardín, de igual modo que Debussy cree encontrar dicha esencia en la habanera. Según Carmen Añón,

la fina sensibilidad de Winthuysen intuyó inmediatamente el enorme peso [que el parque de María Luisa] podría tener en un momento en que, paradójicamente, y dentro de una corriente historicista arquitectónica, en los jardines se reflejaba un mal entendido "exotismo", y trasnochadas corrientes paisajistas llegaban hasta el interior de nobles casas sevillanas, el propio Alcázar, el parque de San Telmo, etc., sin comprender que la esencia del jardín sevillano es algo más sutil y complejo que un azulejo, una fuente o ridículos pastiches ["una jaula de monos con azulejos", escribe Winthuysen] $]^{23}$.

Reconoció Winthuysen el mérito de Forestier, del que dice que "en la reforma del parque tuvo necesariamente que acomodarse a la expansión pública, consiguiendo armonizar el conjunto sin desvirtuar la esencia del carácter, iniciando con esta obra el resurgimiento" ${ }^{24}$. Tal admiración por Forestier llevará a Winthuysen a escribirle en diciembre de 1916 para transmitirle su intención de ir a París para trabajar y aprender con él. Lamentablemente, Winthuysen tuvo que desistir de su empeño al serle denegada la pensión de estudios. Finalmente, en 1919 obtendría, con la recomendación 
de Sorolla y Juan Ramón Jiménez, una beca de la Junta de Ampliación de Estudios para realizar una investigación sobre los jardines históricos españoles.

Más allá de la coincidencia en París de Falla y Winthuysen en los mismos años (Falla, entre 1907 y 1914; el paisajista llega la primera vez en 1904 y vuelve en 1912), es notable el paralelismo entre la admiración de Falla por Debussy y la que le expresaba Winthuysen a Forestier en 1916. Ciertamente, la estrecha amistad que hubo entre los dos músicos no es comparable con la relación a distancia -y meramente intelectual- que mantuvieron Winthuysen y Forestier. Sin embargo, en ambos casos esa afinidad se apoya en la atracción del colega francés por España, y en la aprobación, por parte de los españoles, de las recreaciones alhambristas que elaboran tanto Debussy como Forestier.

Winthuysen ahondará más que Forestier en el concepto mismo del jardín andaluz -domesticidad, continuidad de la casa e intimidad- dejando sus elementos formales reconocibles -azulejos, tiestos- en un segundo plano.

Forestier llegó a Barcelona en 1915, recomendado por el pintor José María Sert, para intervenir en el ajardinamiento de distintas áreas con una superficie de más de 300.000 $\mathrm{m}$, sin contar paseos, veredas y plazas, que alojarían la Exposición Internacional de Barcelona de 1929. Destacan en este proyecto el Parque Laribal (1916) con su majestuosa pérgola, la Rosaleda (1918), y el jardín de Miramar, donde Forestier plasmó, más que en ningún otro, el ideario mediterraneísta que le demandaban los nacionalistas. Dicha mediterraneidad, integrada dentro del discurso noucentista, se expresó mediante un clasicismo de herencia francesa, pero Forestier no pudo renunciar a algunos elementos islámicos trasplantados desde Andalucía. El ejemplo paradigmático es la Escalera-Fuente del Generalife, que conecta los jardines de Amargó y del Teatro Griego con Laribal. Una vegetación mediterránea de cítricos, algarrobos, higueras, encinas, sauces, plátanos, cipreses, rosas, claveles y plantas aromáticas se extiende por toda la montaña ${ }^{25}$.

Algunos autores españoles, no obstante, critican la interpretación que hace Forestier de lo andaluz por considerarla superficial y exotizante. Es el caso de Consuelo Correcher, para quien la prueba de esta estética "pseudo-española" y "vulgarizante" es la aplicación de los trazados y elementos andalusíes en el ajardinamiento de Montjuïc, cuyas pendientes y apertura al mar reclamaban un trazado distinto al del Parque de María Luisa ${ }^{26}$. Y le acusa a Forestier de no "saber que los árboles de España no son palmeras, sino encinas,

25 DOMÍNGUEZ PELÁEZ (1994): 87.

26 MARTÍNEZ CORRECHER (2003): 74. alcornoques, fresnos, olmos, álamos, olivos, castaños y robles".

Resulta sorprendente leer en el artículo de Correcher el asombro por la "inexplicable supeditación a lo foráneo" que mostró el ayuntamiento de Sevilla con su encargo a un paisajista francés, escudándose precisamente en el ejemplo de nuestros músicos y su "espíritu renovador basado en las raíces auténticas del arte". Ignora Consuelo Correcher que los Albéniz, Falla, Granados... también veían a España a través de Europa -por ejemplo, el impresionismo francés-, y cómo el propio Falla había reconocido la maestría de Debussy para captar la esencia de lo español a pesar de la habanera. Esta búsqueda de la identidad española a través de la mirada francesa no es un fenómeno aislado, ni intrínsecamente negativo, sino una realidad que fomentó en los artistas españoles la búsqueda de su propia identidad mediante la síntesis de elementos propios y foráneos.

\section{GRANADA SEGÚN DEBUSSY Y FORESTIER: ANÁLISIS COMPARADO Y TRASCENDENCIA HISTÓRICA}

Tanto Debussy como Forestier representan, en sus respectivas disciplinas, la transición a la modernidad desde una mirada nostálgica a otras culturas: ambos autores transforman ese exotismo en el motor que renovará su lenguaje compositivo. Su recurrente inspiración andaluza ejercerá una gran influencia en los autores españoles y en la configuración de nuestra identidad artística, pero siempre bajo supuestos estéticos y formales muy renovadores respecto de sus predecesores.

Así, mientras Debussy utiliza las escalas andaluzas en su progresivo enriquecimiento de la armonía tonal, Forestier encuentra en los patios granadinos la simplicidad que reclama para los jardines, y que lo alejan de la gran tradición de Le Nôtre, el jardinero creador de Versalles. En ambos casos la aportación principal es la síntesis de elementos exóticos y contemporáneos en la estructura general de la obra, al margen de algunos tópicos que pueden considerarse anecdóticos.

En el caso de Debussy, ya se ha explicado cómo el recurso repetido a la habanera se españoliza cuando es reducido a un bajo ostinato, se armoniza en el modo frigio o se combina con rasgueados guitarrísticos. El bajo ostinato, tan recurrente en Debussy, recrea una atmósfera cerrada, claustrofóbica, comparable al hortus conclusus del patio nazarí. Los momentos puntuales de expansión melódica no disimulan la atmósfera de misterio e intimidad que nos transmiten sus evocaciones de los jardines andaluces.

Por su parte, la azulejería y las "fuentes de los leones" a las que era tan adepto Forestier quedan en segundo plano 
si tenemos en cuenta la concepción estética y espacial que inspiran sus jardines españoles: la importancia del agua, de los aromas y los trazados claros y regulares se convierten en los pilares de su estilo, a medio camino entre el eclecticismo romántico y el racionalismo de Le Corbusier. Se trata de un jardín moderno, que no renuncia sin embargo a la sensualidad nazarí y al reclamo del placer.

\begin{tabular}{|l|l|}
\hline \multicolumn{1}{|c|}{ CLAUDE DEBUSSY } & \multicolumn{1}{|c|}{ J.C.N. FORESTIER } \\
\hline $\begin{array}{l}\text { Escalas andaluzas que en- } \\
\text { riquecen la armonía tonal }\end{array}$ & $\begin{array}{l}\text { Simplicidad del patio gra- } \\
\text { nadino vs. magnificencia } \\
\text { del jardín clásico francés }\end{array}$ \\
\hline $\begin{array}{l}\text { Uso recurrente del bajo os- } \\
\text { tinato: atmósfera cerrada }\end{array}$ & $\begin{array}{l}\text { Hortus conclusus del patio } \\
\text { nazarí: intimidad domésti- } \\
\text { ca }\end{array}$ \\
\hline Falso tópico de la habanera & $\begin{array}{l}\text { Azulejería, escaleras de } \\
\text { agua, "fuentes de los leo- } \\
\text { nes" }\end{array}$ \\
\hline
\end{tabular}

En el "jardín de iris" de Bagatelle se sintetizan los elementos más característicos del jardín impresionista de Monet y de los patios andaluces que ya había conocido Forestier desde 1911. En Bagatelle encontramos numerosas especies fetiches de Monet, entre ellas los lirios en exuberantes composiciones cromáticas inspiradas en Giverny. La influencia hispanoárabe se ve en su carácter de jardín cerrado, concebido como una "habitación exterior" y algunas referencias arquitectónicas ${ }^{27}$. Por ello el jardín parisino es un claro exponente del maridaje entre impresionismo y andalucismo que tan bien desarrollarían musicalmente Debussy y Falla.

En este delicado equilibrio entre tradición y modernidad, Forestier incorpora al jardín andaluz emparrados, nenúfares y crisantemos que se integran fácilmente en el marco neoárabe. Según Dorothée Imbert, "Forestier se apoya en el gusto y en el sentimiento, rompiendo todas las reglas de composición de la jardinería de la época" ${ }^{28}$. Se trata de un exotismo híbrido del que también bebe Debussy, cuando en sus Images para orquesta se inspira indistintamente en la música inglesa, española y francesa. En realidad, el catálogo instrumental y orquestal de Debussy revela esa variedad de referencias históricas y espaciales, desde el gamelán balinés al jazz, desde las canciones infantiles hasta las leyendas bretonas, pasando por la tradición clavecinística francesa. Todas ellas no son sino la fuente de nuevas armonías y texturas que se plantean como alternativa a la tradición romántica, del mismo modo que Forestier combate el modelo paisajis- ta con un eclecticismo renovado según los nuevos usos del espacio público.

Como explica Cristina Domínguez Peláez, este eclecticismo está "siempre al servicio de un principio fundamental: el de la adaptación al medio tanto desde un punto de vista climatológico como histórico". Forestier admira a Le Nôtre, pero cree necesario evolucionar a la simplicidad y a planteamientos universalistas, entendiendo esta universalidad "como suma de localismos reinterpretados por el artista. Cuanto más amplio sea el repertorio, más recursos creativos estarán a su alcance" ${ }^{29}$. Una vez más, la afinidad con Debussy, y sobre todo con Falla, se pone de manifiesto: en los jardines de Forestier, "islamismo y latinidad son [...] las influencias que inciden con mayor fuerza" ${ }^{30}$, junto a los tintes paisajistas en las perspectivas, abiertas o cerradas por la vegetación, el aterrazamiento babilónico y la geometría francesa.

En el caso del regionalismo sevillano, que conoció tan de cerca, Forestier demostró el calado popular de su propuesta que adaptaba las raíces andalusíes a los tiempos modernos: “... les amants de Séville verront se refléter ici les beautés artistiques de la villa, héritage inestimable du passé, mais ils verront également l'actualité artistique unie intimement au progrès dans une renaissance providentielle..." ${ }^{\prime 31}$.

Y todo ello en aras de combatir el cliché español de la España de pandereta, objetivo en el que Forestier se implica muy directamente: “... notre désir est de montrer [...] tout ce qui représente le trésor d'une ville qui a conscience de sa mission pour la gloire de l'Andalousie et de l'Espagne: voilà ce qui est le passé et le présent, l'authentique, ce que nous devons communiquer à la face du monde..." 32 .

El eclecticismo que alimenta todos los jardines públicos y privados de Forestier muestra el éxito comercial de su estilo en los dos países, España y Francia. La predisposición del público hacia lo exótico a comienzos del s. XX fue aprovechada también por nuestros músicos afincados en París y por los propios franceses. Ejemplo único de jardín

29 DOMÍNGUEZ PELÁEZ (1994): 85.

30 DOMÍNGUEZ PELÁEZ (1994): 85.

31 “... los amantes de Sevilla verán reflejadas aquí las maravillas artísticas de la ciudad, herencia inestimable del pasado, pero verán también la actualidad artística íntimamente unida al progreso en un renacimiento providencial...". FORESTIER, J.C.N., texto publicado en Betica, II année, $\mathrm{n}^{\circ}$ 20, 20 novembre 1914, Sevilla, y recogido por ASSASSIN (1994): 112.

32 "... nuestro deseo es mostrar todo lo que representa el tesoro de una ciudad consciente de su misión por la gloria de Andalucía y España; he aquí el pasado y el presente, lo auténtico, lo que debemos transmitir al mundo...”. FORESTIER, J.C.N., texto publicado en Betica, II année, ${ }^{\circ}$ 20, 20 novembre 1914, Sevilla, y recogido por ASSASSIN (1994): 112. 
"hispanoárabe" en Francia es el de Joseph Guy, en Béziers, donde Forestier recrea un decorado andaluz muy inspirado en los jardines de Sevilla y Granada ${ }^{33}$. El público francés y la aristocracia española demandan exotismo andalusí, y tanto Debussy como Forestier utilizan esta moda para buscar las esencias de lo español mientras renuevan su lenguaje en la transición al arte de vanguardia.

\section{BIBLIOGRAFÍA}

Añón Feliú, Carmen, “Javier de Winthuysen”, Carmen Añón Feliú et al., Javier de Winthuysen: jardinero: Andalucía, Sevilla, Consejería de Obras Públicas y Transportes, 1989: 18-33.

Aracil, Alfredo, "Sonido y sentido del jardín", Alfredo Aracil (ed.), Música y jardines, Granada, Publicaciones del Archivo Manuel de Falla, 2003: 7-29.

Assassin, Sylvie, "L’Exposition Ibéro-Américaine de Séville", Benedicte Leclerc (dir.), J.C.N. Forestier (18611930). Du jardin au paysage urbain. Colloque International sur J.C.N. Forestier (1990, Paris). París, Picard, 1994: 111-120.

Audurier Cros, Alix, "Le jardin Joseph Guy de Béziers", Benedicte Leclerc (dir.), J.C.N. Forestier (1861-1930). Du jardin au paysage urbain. Colloque International sur J.C.N. Forestier (1990, Paris). París, Picard, 1994: 121-132.

Martínez Correcher, Consuelo, "Los jardines del mundo de Manuel de Falla", Alfredo Aracil (ed.): Música y jardines, Granada, Publicaciones del Archivo Manuel de Falla, 2003: 57-101.

Domínguez Peláez, Cristina, "Los jardines en España”, Benedicte Leclerc (dir.), J.C.N. Forestier (1861-1930). $D u$ jardin au paysage urbain. Colloque International sur J.C.N. Forestier (1990, Paris), París, Picard, 1994: 83-97.

Falla, Manuel de, "Claude Debussy y España”, Revue Musicale, diciembre de 1920, Manuel de, Escritos sobre música y músicos, Madrid, Espasa-Calpe, 1988: 7278.

Forestier, Jean-Claude Nicolas, Jardines. Cuadernos de dibujos y planos. Barcelona, Stylos, 1991 (primera ed.: París, c. 1920).

Gallego, Antonio, "Noche, música y jardín. Sonidos y perfumes nocturnos en las lecturas de Manuel de Falla", Alfredo Aracil (ed.), Música y jardines, Granada, $\mathrm{Pu}-$ blicaciones del Archivo Manuel de Falla, 2003: 103123.

Imbert, Dorothée, "Tracé architectonique et poétique végétale", Benedicte Leclerc (dir.): J.C.N. Forestier (1861-1930). Du jardin au paysage urbain. Colloque International sur J.C.N. Forestier (1990, Paris), París, Picard, 1994: 69-81.

Jambou, Louis, "Por los jardines musicales del Renacimiento", Alfredo Aracil (ed.), Música y jardines, Granada, Publicaciones del Archivo Manuel de Falla, 2003: 3156.

Mandó, Bernard, "Bagatelle", Benedicte Leclerc (dir.), J.C.N. Forestier (1861-1930). Du jardin au paysage urbain. Colloque International sur J.C.N. Forestier (1990, Paris), París, Picard, 1994: 53-67.

Nieto Caldeiro, Sonsoles, "La Sevilla reformada", Benedicte Leclerc (dir.), J.C.N. Forestier (1861-1930). Du jardin au paysage urbain. Colloque International sur J.C.N. Forestier (1990, Paris), París, Picard, 1994: 99110.

Nommick, Yvan, "Jardines en la música instrumental desde los Jeux d'eau à la Villa d'Este hasta Noches en los jardines de España", Alfredo Aracil (ed.), Música y jardines, Granada, Publicaciones del Archivo Manuel de Falla, 2003: 125-153.

Persia, Jorge de, En torno a lo español en la música del siglo XX, Granada, Diputación de Granada, 2003a.

Persia, Jorge de, "Jardín, paisaje y música en el pensamiento artístico en tiempos de Rusiñol”, Alfredo Aracil (ed.), Música y jardines, Granada, Publicaciones del Archivo Manuel de Falla, 2003b: 155-175.

Stefulesco, Caroline, "Giverny ou la quête du couleur. Le jardin d'un peintre impressioniste", Carmen Añón Feliú (dir.), Jardines y paisajes en el arte y en la historia, Madrid, Editorial Complutense, 1995: 281-289.

Tarragó i Cid, Salvador, "Entre Le Nôtre y Le Corbusier", Benedicte Leclerc (dir.), J.C.N.Forestier (1861-1930). Du jardin au paysage urbain. Colloque International sur J.C.N.Forestier (1990, Paris), París, Picard, 1994: 253-266.

Velly, Jean-Jacques, "Ibéria: la rencontre de deux visions d'une Espagne idéalisée", Louis Jambou (ed.), $L a$ musique entre France et Espagne. Interactions stylisques 1870-1939, París, Université Paris IV-Sorbonne, 2003: 307-318.
Recibido: 22.05 .2016

Aceptado: 16.02.2017 